\title{
GLAUCOMA IN PUNJAB- AN OBSERVATIONAL STUDY
}

\author{
Ruchi Singh ${ }^{1}$, Asheesh Bajaj2, Sharad Kumar Mishra ${ }^{3}$
}

${ }^{1}$ Registrar, Sankara Eye Hospital, Ludhiana.

${ }^{2} \mathrm{CMO}$, Sankara Eye Hospital, Ludhiana.

${ }^{3}$ Registrar, Sankara Eye Hospital, Kanpur.

\section{ABSTRACT}

\section{BACKGROUND}

Glaucoma is the second leading cause of blindness in the adult population in India. The global prevalence of glaucoma for population aged 40 to 80 years is estimated to be $3.54 \%$ and the projected number of people with glaucoma worldwide will increase to 111.8 million in 2040. This creates a need for early diagnosis and prompt management of glaucoma, especially in the underprivileged rural areas that lack awareness and facilities. These estimates are important in guiding the designs of glaucoma screening, treatment and related public health strategies.

Purpose of Study- To determine the demographic distribution of glaucoma and its types in Punjab.

\section{MATERIALS AND METHODS}

This study included total of 4355 patients who were screened for cataract surgery from Eye camps. Glaucoma was diagnosed as per International Society of Geographical and Epidemiological Ophthalmology (ISGEO) classification.

\section{RESULTS}

Out of 4355 patients, 149 (3.42\%) patients had Primary Open Angle Glaucoma (POAG) and 2 (0.04\%) patients had Primary Angle Closure Glaucoma (PACG). Patients with glaucoma in our study were $3.46 \%$.

\section{CONCLUSION}

The numbers of glaucoma patients are rapidly increasing in Punjab, especially in Ludhiana and nearby district and it is in accordance with the prevalence in rest of India.

\section{KEYWORDS}

Glaucoma, POAG, PACG.

HOW TO CITE THIS ARTICLE: Singh R, Bajaj A, Mishra SK. Glaucoma in Punjab- an observational study. J. Evolution Med. Dent. Sci. 2017;6(44):3474-3476, DOI: $10.14260 / J e m d s / 2017 / 750$

\section{BACKGROUND}

Glaucoma, the second leading cause of global irreversible blindness, is estimated to have affected over 60.5 million individuals worldwide. ${ }^{1}$ The word Glaucoma is derived from Greek meaning "clouded" and is defined as a disturbance of the structural and functional integrity of the optic nerve that can be arrested of diminished by adequate lowering of IOP. ${ }^{2}$

There are many types of glaucoma, out of which primary open angle glaucoma is most common in Western countries.3,4,5 Primary open angle glaucoma is characterised as a multifactorial optic neuropathy with a characteristic acquired atrophy of the optic nerve and loss of retinal ganglion cells and their axons developing in the presence of open anterior chamber angles and manifesting characteristic of visual field abnormalities. In contrast all other types of glaucoma, invariably the secondary glaucomas and historically even the POAG are defined first and foremost by the presence of elevated IOP and not in reference to the optic neuropathy that follows sustained elevated IOP's. ${ }^{2}$ Closed

Financial or Other, Competing Interest: None.

Submission 27-04-2017, Peer Review 22-05-2017,

Acceptance 27-05-2017, Published 01-06-2017.

Corresponding Author:

Dr. Ruchi Singh,

W/o. Dr. Abhishek Samuel,

H. No. 4, New Staff Colony,

Christian Medical College,

Ludhiana-141008, Punjab.

E-mail: ruchi2abhi@rediffmail.com

DOI: $10.14260 /$ jemds $/ 2017 / 750$

\section{(c) $(7)(-$}

angle glaucoma cases are less than $10 \%$ in United States and Europe, but in other countries particularly Asian countries it is almost half of glaucoma patients. ${ }^{6}$

The estimated prevalence of glaucoma for India was 11.9 million in a study conducted in the late 1990s. The number of glaucoma patients has only increased since then. ${ }^{1,7,8}$ The National Blindness Survey 2001 showed that glaucoma is the third major cause of blindness in India and responsible for $5.9 \%$ of blindness (VA < 6/60). ${ }^{9}$ At present more than 3 million people in the world are blind due to glaucoma. ${ }^{10}$ The number of people with glaucoma worldwide will increase to 111.8 million in 2040, disproportionately affecting people residing in Asia and Africa. These estimates are important in guiding the designs of glaucoma screening, treatment and related public health strategies. ${ }^{11}$ Early detection of glaucoma is often difficult due to its asymptomatic course in the initial stage, as also the lack of a viable screening tool. Studies have shown that $50 \%-90 \%$ of the glaucoma cases remain undiagnosed.12

The high rates of blindness in India can be explained by the large proportion of undiagnosed disease. Early case detection rate is of utmost importance to reduce the disease burden in the rural population, where awareness in terms of routine eye screening is very low. ${ }^{13}$ Till now seven population based studies have been reported in India, out of which three are from Tamil Nadu, one from Andhra Pradesh, two from Bengal and one from Amritsar (Punjab). ${ }^{13-20}$ All the seven studies have variation in prevalence data; it is because they have used different diagnostic criteria. There is a lack of data in Punjab and only one study so far is published.13 The 
current study is not a prevalence study, rather it is an observational study and the motive behind this study is to find the demographic distribution of glaucoma and also its types. As there is only one study prior to this study, this study along with the previous study will help in planning epidemiological surveys in Punjab. Prior to this study, there have been no data published in Ludhiana district and its adjoining areas.

\section{MATERIALS AND METHODS}

This study was conducted at Sankara Eye Hospital, Ludhiana for a period of one year from $1^{\text {st }}$ September 2014 till $31^{\text {st }}$ August 2015. This was an observational study. This study included total of 4355 patients who were screened for cataract surgery from Eye camps from the nearby districts around Ludhiana, Punjab. Written informed consent was obtained from all the patients posted for cataract surgery. Detailed history and ophthalmic examination was done. Examination included slit lamp biomicroscopy, applanation tonometry, gonioscopy, central corneal thickness, indirect ophthalmoscopy as well as stereo biomicroscopy of the disc and macula (using non-contact $+90 \mathrm{D}$ lens). When glaucoma was suspected, visual field testing was done.

Glaucoma was diagnosed as per International Society of Geographical and Epidemiological Ophthalmology (ISGEO) classification, in which cases are diagnosed on the grounds of both structural and functional evidence of glaucomatous optic neuropathy. ${ }^{21}$
The International Society of Geographical and Epidemiologic Ophthalmology (ISGEO) classification proposed by Foster et $\mathrm{al}^{22}$ for use in population-based studies. The ISGEO criterion is given in Table 1.

\section{RESULTS}

Total of 4355 patients were screened in the study, out of which 151 (3.46\%) were identified to be having glaucoma. Most of the patients in the study were in the age group 60 69 years, which was 68 patients. In the age group $70-79$ years there were 39 patients, in the age group 50 - 59 years there were 22 patients, in the age group more than 80 years there were 14 patients, in the age group 40 - 49 years there were 5 patients and in age group 30 - 39 years there were 3 patients (Fig. 1). Minimum age in our study was 35 years and maximum age was 98 years. The mean age was 64.9 years. From the selected 151 patients who were diagnosed to have glaucoma, 103 patients $(68.2 \%)$ were male and 48 (32.57\%) were female.

Out of total of 151 patients who were diagnosed as glaucoma screened from various camps conducted all over the Punjab area, 149 (98.6\%) patients had Primary Open Angle Glaucoma (POAG) and $2(1.32 \%)$ patients had Primary Angle Closure Glaucoma (PACG) (Table 2). There were 101 male patients who had POAG (Table 3 ) out of 151 subjects who were diagnosed as glaucoma.

\begin{tabular}{|c|c|c|c|c|}
\hline Category & $\begin{array}{l}\text { Visual } \\
\text { Acuity }\end{array}$ & IOP & Optic Disc & Field Defect \\
\hline $\begin{array}{l}\text { Category } 1 \text { Diagnosis } \\
\text { (structural and functional } \\
\text { evidence) }\end{array}$ & - & - & 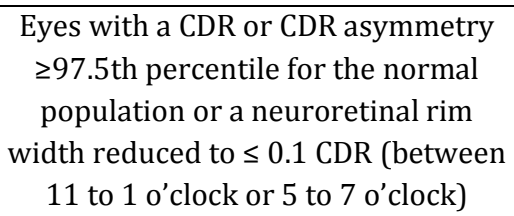 & $\begin{array}{l}\text { Definite visual field } \\
\text { defect consistent } \\
\text { with glaucoma }\end{array}$ \\
\hline $\begin{array}{l}\text { Category } 2 \text { Diagnosis } \\
\text { (advanced structural } \\
\text { damage with unproved } \\
\text { field loss) }\end{array}$ & - & - & $\begin{array}{l}\text { CDR or CDR asymmetry } \geq 99.5 \text { th } \\
\text { percentile for the normal population, } \\
\text { glaucoma was diagnosed solely on } \\
\text { the structural evidence }\end{array}$ & $\begin{array}{l}\text { Subject could not } \\
\text { satisfactorily } \\
\text { complete visual } \\
\text { field testing }\end{array}$ \\
\hline $\begin{array}{c}\text { Category } 3 \text { Diagnosis } \\
\text { (Optic disc not seen. Field } \\
\text { test impossible) } \\
\text { A }\end{array}$ & $3 / 60$ & $\begin{array}{l}\text { IOP > 99.5th percentile } \\
\text { for the normal population }\end{array}$ & $\begin{array}{l}\text { It is not possible to examine } \\
\text { the optic disc }\end{array}$ & Field test not done \\
\hline B & $<3 / 60$ & $\begin{array}{l}\text { Evidence of glaucoma filtering } \\
\text { surgery or medical records } \\
\text { were available confirming } \\
\text { glaucomatous visual morbidity }\end{array}$ & $\begin{array}{l}\text { It is not possible to } \\
\text { examine the optic disc }\end{array}$ & Field test not done \\
\hline \multicolumn{5}{|c|}{$\begin{array}{l}\text { Table 1. The Diagnosis of Glaucoma in Cross-Sectional Prevalence Surveys } \\
\text { (The Diagnosis is made according to Three Levels of Evidence) }\end{array}$} \\
\hline
\end{tabular}

\begin{tabular}{|c|c|}
\hline Type of Glaucoma & No. of Patients \\
\hline POAG & $149(3.42 \%)$ \\
\hline PACG & $2(0.04 \%)$ \\
\hline Total & $151(3.46 \%)$ \\
\hline \multicolumn{2}{|c|}{ Table 2. Distribution of Glaucoma in the Study Population } \\
\hline
\end{tabular}

\begin{tabular}{|c|c|c|}
\hline Type of Glaucoma & Male & Female \\
\hline POAG & 101 & 48 \\
\hline PACG & 2 & 0 \\
\hline Total & $\mathbf{1 0 3}(\mathbf{6 8 . 2 \% )}$ & $\mathbf{4 8}(\mathbf{3 2 . 5 7 \% )}$ \\
\hline \multicolumn{2}{|c|}{ Table 3. Distribution of Glaucoma according to Gender } \\
\hline
\end{tabular}

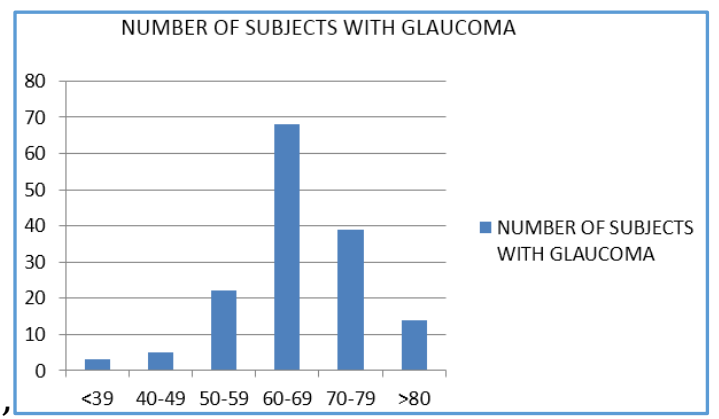

Figure 1. Age Wise Distribution of Glaucoma Patients 


\section{DISCUSSION}

The estimated global prevalence of glaucoma was found to be $3.54 \%$ in a systematic meta-analysis in 2014 with the highest prevalence in Africa. ${ }^{11}$ In our study, $3.46 \%$ patients were found to have glaucoma. There were so many patients who turned up for screening camps and it can be related with better socioeconomic status in this part of country even in rural areas.

Maximum number of patients (3.42\%) in our study had POAG, which was in accordance with Quigley et al ${ }^{1}$ and the Hooghly River Glaucoma Study. ${ }^{16}$ In contrast to this, Sharma et $\mathrm{al}^{13}$ found more number of patients with PACG in their study.

Many studies noted that prevalence of glaucoma increased with age. ${ }^{23,15}$ This was also seen in our study. There were only 5 patients in the age group $40-49$, but as the age group increased the number of patients with glaucoma increased. Mean age in our study was 64.9 years and mean age of POAG was 65.02 years. This was also reported by Das et al. ${ }^{21}$ They reported mean age of POAG as 60.54 years. Sharma et al also found mean age at presentation of Primary Open Angle Glaucoma (POAG) as $60.8 \pm 9.105$ years. ${ }^{13}$ Due to these findings, patients above 50 years should be kept in high risk group for glaucoma and it should be investigated.

Male patients had preponderance in our study and were $68.2 \%$ in our study. Out of 151 patients, we had 101 patients with POAG who were male. Male dominance in POAG was also reported by Das et al, ${ }^{21}$ George et al $^{23}$ and also by Sharma et al. ${ }^{13}$

\section{CONCLUSION}

The numbers of glaucoma patients are rapidly increasing in Punjab, especially in Ludhiana and nearby district and it is in accordance with the prevalence in rest of India. Though these numbers are just a tip of the iceberg, so in order to find exact prevalence early case detection and treatment is of utmost importance. In order to identify and treat such patients, more comprehensive eye screening camps should be carried out in different areas of Punjab and awareness should be spread.

\section{Limitations of Study}

In this study, the no. of patients who were observed to have glaucoma were actually picked up from screening camps for cataract. The screening camps were not for glaucoma per se.

\section{REFERENCES}

[1] Quigley HA, Broman AT. The number of people with glaucoma worldwide in 2010 and 2020. $\mathrm{Br} \mathrm{J}$ Ophthalmol 2006;90(3):262-7.

[2] Stamper RL, Lieberman MF, Drake MV. Primary angle closure glaucoma. Becker-Shaffer's diagnosis and therapy of the glaucomas. $8^{\text {th }}$ ed. St. Louis: Mosby 2009.

[3] Rahmani B, Tielsch JM, Katz J, et al. The cause-specific prevalence of visual impairment in an urban population. The Baltimore eye survey. Ophthalmology 1996;103(11):1721-6.

[4] Coffey M, Reidy A, Wormald R, et al. Prevalence of glaucoma in the west of Ireland. British Journal of Ophthalmology 1993;77(1):17-21.

[5] Quigley HA, Vitale S. Models of open-angle glaucoma prevalence and incidence in the United States. Invest Ophthalmol Vis Sci 1997;38(1):83-91.
[6] Scharioth GB. From deep sclerectomy to canaloplasty: Re-establishing the natural outflow in patients with chronic-angle glaucoma. In: surgical techniques in Ophthalmology- Glaucoma Surgery. New Delhi: Jaypee Brothers Medical Publisher Ltd 2010:308-17.

[7] Kingman S. Glaucoma is second leading cause of blindness globally. Bull world health Organ 2004;82(11):887-8.

[8] Wong TY, Loon SC, Saw SM. The epidemiology of age related eye diseases in Asia. $\mathrm{Br} \mathrm{J}$ Ophthalmol 2006;90(4):506-11.

[9] Murthy GV, Gupta SK, Bachani D, et al. Current estimates of blindness in India. Br J Ophthalmol 2005;89(3):257-60.

[10] Pascolini D, Mariotti SP. Global estimates of visual impairment: 2010. Br J Ophthalmol 2012;96(5):614-8.

[11] Tham YC, Li X, Wong TY, et al. Global prevalence of glaucoma and projections of glaucoma burden through 2040: a systematic review and meta-analysis. Ophthalmology 2014;121(11):2081-90.

[12] Rewri P, Kakkar M. Awareness, knowledge, and practice: a survey of glaucoma in north Indian rural residents. Indian J Ophthalmol 2014;62(4):482-6.

[13] Sharma S, Gupta K, Kaur P, et al. Clinical profile and subtypes of glaucoma in northern India. Scholars Academic Journal of Biosciences 2015;3(9):766-73.

[14] Dandona L, Dandona R, Srinivas M, et al. Open-angle glaucoma in an urban population in southern India: the Andhra Pradesh eye disease study. Ophthalmology 2000;107(9):1702-9.

[15] Ramakrishnan R, Nirmalan PK, Krishnadas R, et al. Glaucoma in rural population of southern India: the Aravind comprehensive eye survey. Ophthalmology 2003;110(8):1484-90.

[16] Paul C, Sengupta S, Choudhury S, et al. Prevalence of glaucoma in eastern India: the Hooghly river glaucoma study. Indian Journal of Ophthalmology 2016;64(8):578-83.

[17] Krishnadas R, Puthuran GV. Prevalence of glaucoma in India and the world. Tamil Nadu Journal of Ophthalmology 2009;47:14-6.

[18] Jacob A, Thomas R, Koshi SP, et al. Prevalence of primary glaucoma in an urban south Indian population. Indian J Ophthalmol 1998;46(2):81-6.

[19] Vijaya L, George R, Paul PG, et al. Prevalence of openangle glaucoma in a rural south Indian population. IOVS 2005;46(12):4461-7.

[20] Raychaudhuri A, Lahiri SK, Bandyopadhyay M, et al. A population based survey of the prevalence and types of glaucoma in rural West Bengal: the West Bengal glaucoma study. Br J Ophthalmol 2005;89(12):155964.

[21] Das J, Bhomaj S, Chaudhuri Z, et al. Profile of glaucoma in a major eye hospital in north India. Indian J Ophthalmol 2001;49(1):25-30.

[22] Foster PJ, Buhrmann R, Quigley HA, et al. The definition and classification of glaucoma in prevalence surveys. The British Journal of Ophthalmology 2002;86(2):238-42.

[23] George R, Lingam V. Prevalence of glaucoma in India: a review. Journal of Current Glaucoma Practice 2007;1(2):7-11. 